\title{
Propofol depresses cisplatin cytotoxicity via the inhibition of gap junctions
}

\author{
YUAN ZHANG $^{1 *}$, XIYAN WANG ${ }^{2 *}$, QIN WANG $^{1}$, HUI GE $^{2}$ and LIANG TAO ${ }^{1}$ \\ ${ }^{1}$ Department of Pharmacology, Zhongshan School of Medicine, Sun Yat-Sen University, Guangzhou, Guangdong 510080; \\ ${ }^{2}$ Tumor Research Institute, Xinjiang Medical University Affiliated Tumor Hospital, Urumqi, Xinjiang 830000, P.R. China
}

Received April 6, 2015; Accepted February 15, 2016

DOI: $10.3892 / \mathrm{mmr} .2016 .5119$

\begin{abstract}
The general anesthetic, propofol, affects chemotherapeutic activity, however, the mechanism underlying its effects remains to be fully elucidated. Our previous study showed that tramadol and flurbiprofen depressed the cytotoxicity of cisplatin via the inhibition of gap junction (GJ) intercellular communication (GJIC) in connexin (Cx)32 HeLa cells. The present study investigated whether the effects of propofol on the cytotoxicity of cisplatin were mediated by GJ in U87 glioma cells and Cx26-transfected HeLa cells. Standard colony formation assay was used to determine the cytotoxicity of cisplatin. Parachute dye coupling assay was used to measure GJ function, and western blot analysis was used to determine the expression levels of $\mathrm{Cx} 32$. The results revealed that exposure of the U87 glioma cells and the Cx26-transfected HeLa cells to cisplatin for $1 \mathrm{~h}$ reduced clonogenic survival in low density cultures (without GJs) and high density cultures (with GJs). However, the toxic effect was higher in the high density culture. In addition, pretreatment of the cells with propofol significantly reduced cisplatin-induced cytotoxicity, but only in the presence of functional GJs. Furthermore, propofol significantly inhibited dye coupling through junctional channels, and a long duration of exposure of the cells to propofol downregulated the expression levels of $\mathrm{Cx} 43$ and $\mathrm{Cx} 26$. These results demonstrated that the inhibition of GJIC by propofol affected the therapeutic efficacy of chemotherapeutic drugs. The present study provides evidence of a novel mechanism underlying the effects of analgesics in counteracting chemotherapeutic efficiency.
\end{abstract}

Correspondence to: Professor Liang Tao, Department of Pharmacology, Zhongshan School of Medicine, Sun Yat-Sen University, 74 Zhongshan 2nd Road, Guangzhou, Guangdong 510080, P.R. China

E-mail: taol@mail.sysu.edu.cn

*Contributed equally

Key words: gap junction, connexin43, connexin26, propofol, cisplatin

\section{Introduction}

Gap junctions (GJs) are plasma membrane channels, which directly connect the cytoplasms of neighboring cells. GJs are composed of two hemichannals, each of which contains six connexin $(\mathrm{Cx})$ proteins for docking to its counterpart in the coupled cell membrane and form a GJ channel (1). GJs provide the direct cell-cell transfer of ions, metabolites and other small molecules, thereby mediating intimate intercellular molecular signaling (2). GJ intercellular communication (GJIC) is essential in diverse processes, including cell growth, differentiation and the maintenance of homeostasis $(3,4)$. Several studies have shown important roles of GJIC in cancer biology (5-7).

It has been reported that the toxicities of cisplatin and oxaliplatin are increased by the presence of GJIC between the target cells $(8,9)$. This enhanced toxicity may be due to the transmission of 'death signals' among adjacent cells via GJs. This effect has been observed in ionizing radiation, in which cells that are not irradiated, but adjacent to irradiated cells, also become damaged or die $(10,11)$. In addition, the enhancement/maintenance of GJIC may enhance the efficacy of cancer treatment, whereas the inhibition of GJIC is likely to decrease the toxicity of chemotherapeutic agents.

Propofol (2,6-diisopropylphenyl) is the most widely used intravenous general anesthetic agent for the induction and maintenance of anesthesia (12), and it is often used during chemotherapy. It has been reported that propofol mediates protective effects against cisplatin-induced injury, including the upregulation of endothelial adhesion molecules in human umbilical vein endothelial cells (13) and the attenuation of toxic oxidative stress (14). In addition, propofol has been shown to suppress GJIC composed of Cx32 in various cell lines $(15,16)$. Our previous studies demonstrated that tramadol and flurbiprofen, two commonly used analgesics, depressed the cytotoxicity of cisplatin via inhibiting GJIC (17). In addition, propofol has been observed to depress the toxicity of X-ray irradiation through inhibition of GJs in Cx32-transfected HeLa cells (18), which suggested that the inhibition of GJIC is one of the possible mechanisms underlying the effects of anesthetic agents against toxic effects during chemotherapy and radiotherapy. However, there remains a lack of evidence of the effects of propofol on the regulation of GJs composed of $\mathrm{Cx} 43$ or $\mathrm{Cx} 26$, and its chemotherapeutic efficiency. 
In the present study, U87 glioma and Cx26-transfected HeLa cells were selected to investigate whether the effects of propofol on the cytotoxicity of cisplatin are mediated by alterations in GJ function. The results of the present study may help elucidate a novel mechanism underlying the effects of analgesics in counteracting chemotherapeutic efficiency.

\section{Materials and methods}

Materials. Propofol and intralipid (10\% soybean oil, 2.25\% glycerol and $1.2 \%$ purified egg phosphatide) were purchased from Sun Yat-Sen Memorial Hospital (Guangzhou, China). G-418, hygromycin and doxycycline were from Calbiochem (San Diego, CA, USA). Calcein-acetoxymethyl ester (calcein-AM) and cell culture reagents were from Invitrogen; Thermo Fisher Scientific, Inc., Waltham, MA, USA). Cisplatin and primary and secondary antibodies for use in western blotting were purchased from Sigma-Aldrich (St. Louis, MO, USA). All other reagents were purchased from Sigma-Aldrich, unless stated otherwise.

Cell lines and cell culture. The human U87 glioma cell line was obtained from American Tissue Culture Collection (Manassas, VA, USA), and the cells $\left(3 \times 10^{4}\right.$ cells/well) were cultured at $37^{\circ} \mathrm{C}$ for 48 h to $70-100 \%$ confluence in Dulbecco's modified Eagle's medium (DMEM) supplemented with $10 \%$ fetal bovine serum. The HeLa cell line expressing the Cx26 gene under the control of a bidirectional tetracycline-inducible promoter, was provided by Dr Andrew L. Harris (Department of Pharmacology and Physiology, New Jersey Medical School, University of Medicine and Dentistry of New Jersey, NJ, USA) and has been described previously (19). The Cx26-expressing HeLa cells were grown at $37^{\circ} \mathrm{C}$ in DMEM supplemented with $10 \%$ fetal bovine serum, $100 \mu \mathrm{g} / \mathrm{ml} \mathrm{G} 418$ sulfate and $200 \mu \mathrm{g} / \mathrm{ml}$ hygromycin $\mathrm{B}$. The $\mathrm{Cx} 26$ coding sequence was followed by an influenza hemagglutinin (HA) epitope tag at the C-terminus, which was incorporated using a Tet-On inducible expression system and one-step anti-haemagglutinin immunoaffinity purification, as previously described (19). Expression of Cx26 was induced by exposure to $1 \mu \mathrm{g} / \mathrm{ml}$ doxycycline for $48 \mathrm{~h}$ at $37^{\circ} \mathrm{C}$.

Sulforhodamine B (SRB) assay. Cell viability was assessed using an SRB assay (20). The cells were seeded in 96-well plates $\left(\sim 3 \times 10^{4}\right)$ and exposed to various concentrations of propofol $(1,5,30$ and $100 \mu \mathrm{M})$ for $48 \mathrm{~h}$ at $37^{\circ} \mathrm{C}$. The medium was then removed, and the cells were fixed with $10 \%(\mathrm{wt} / \mathrm{vol})$ cold trichloroacetic acid for $1 \mathrm{~h}$ at $4^{\circ} \mathrm{C}$, following which the excess dye was removed by washing repeatedly with $1 \%$ ( vol/vol) acetic acid. The protein-bound dye was dissolved in $10 \mathrm{mM}$ Tris base solution for determination of the optical density (OD) at $564 \mathrm{~nm}$ using an Epoch $^{\mathrm{TM}}$ microplate reader (BioTek Instruments, Inc., Winooski, VT, USA).

Standard colony-forming assay. The toxicity of cisplatin was evaluated using a standard colony-forming assay, as described previously (9). The cells were seeded at a high density of 30,000 cells $/ \mathrm{cm}^{2}$ and grown to $90 \%$ confluence, followed by drug treatment. Propofol was added to the cells at $15 \mu \mathrm{M} 4 \mathrm{~h}$ prior to cisplatin treatment. Following exposure to $20 \mu \mathrm{M}$ cisplatin for $1 \mathrm{~h}$ at $37^{\circ} \mathrm{C}$, the cells were washed with phosphate-buffered saline (PBS), trypsinized, counted and reseeded into six-well dishes at a density of 500 cells/well. A low density group was also included, in which the cells were seeded at 500 cells $/ \mathrm{cm}^{2}$ in six-well dishes and treated with cisplatin. In the two culture groups, the cells were incubated for another 5-8 days at $37^{\circ} \mathrm{C}$, and were then fixed and stained with $4 \%$ crystal violet in ethanol. Cells were counted using an Olympus CKX41 inverted microscope (Olympus Corporation, Tokyo, Japan), and colonies containing $\geq 50$ cells were counted. Colony formation was normalized to the number of colonies formed by vehicle-treated $(10 \mu \mathrm{g} / \mathrm{ml}$ lipid emulsion) cells. The surviving fraction was calculated as follows: Surviving fraction $(\%)=$ colonies in cisplatin-treated group/colonies in non-treated group x $100 \%$.

'Parachute' dye-coupling assay. A dye-coupling assay was used to examine GJ function, and was performed as described previously $(19,21)$. Cells were grown to confluence, and the donor cells were labeled with $5 \mu \mathrm{M}$ calcein-AM, which is converted into calcein in the intracellular plasma to permeate through GJs to the adjacent cells, for $30 \mathrm{~min}$ at $37^{\circ} \mathrm{C}$. Donor cells were then trypsinized and seeded onto the receiver cells at a 1:500 donor:receiver ratio. These cells were allowed to attach to the monolayer of the receiver cells to form GJs for $4 \mathrm{~h}$ at $37^{\circ} \mathrm{C}$, and were then monitored under a fluorescence microscope (Olympus IX71; Olympus Corporation). The average number of receiver cells containing calcein per donor cell was determined and normalized to that of the vehicle cultures, and thus considered to be a measurement of the degree of GJ function.

Western blot analysis. The cells were washed with cold PBS three times and then harvested using lysis buffer (22). The cell lysate was sonicated and then centrifuged at $14,167 \mathrm{x}$ g for $30 \mathrm{~min}$ at $4^{\circ} \mathrm{C}$. Proteins were quantified using a DC protein assay kit (Bio-Rad Laboratories, Inc., Hercules, CA, USA). Subsequently, $25 \mu \mathrm{g}$ proteins from each sample were separated by SDS-PAGE and then transferred onto a nitrocellulose membrane. Membranes were blocked with 5\% milk for $1 \mathrm{~h}$ at room temperature and incubated with the mouse monoclonal primary antibodies against $\mathrm{Cx} 43$ (C8093; diluted 1:3,000 in 5\% milk), HA IgG [H9658; diluted 1:1,000 in Tris-buffered saline with Tween 20 (TBST)] and $\beta$-actin (A1978; diluted 1:10,000 in $5 \%$ milk) at $4^{\circ} \mathrm{C}$ overnight. Membranes were subsequently washed three times with TBST for 10 min and incubated with mouse anti-goat secondary antibody (88704) against $\mathrm{Cx} 43$ (diluted 1:6,000 in 5\% milk), HA $\operatorname{lgG}$ (diluted 1:2,000 in TBST), and $\beta$-actin (diluted 1:10,000 in 5\% milk) for $1 \mathrm{~h}$ at room temperature. The membranes subsequently were washed three times with TBST for $10 \mathrm{~min}$. Immunopositive bands were visualized using the Amersham ECL ${ }^{\mathrm{TM}}$ Plus Western Blotting Detection kit (GE Healthcare Life Sciences) and protein expression levels were quantified using a GeneGenius Bio Imaging system (version 1.2; Syngene, Frederick, MD, USA).

Statistical analysis. Differences between groups were statistically analyzed using an unpaired Student's $t$-test and the results are presented as the mean \pm standard error of the mean using Sigma Plot 10.0 software (Jandel Scientific, San Rafael, 
CA, USA). $\mathrm{P}<0.05$ was considered to indicate a statistically significant difference.

\section{Results}

Effects of propofol on cisplatin cytotoxicity. As shown in Fig. 1, the effects of propofol on cisplatin toxicity were determined in the U87 and Cx26-transfected HeLa cells. Propofol was used at a concentration of $15 \mu \mathrm{M}$, which is the $50 \%$ effective concentration (EC50) in humans (23), for $4 \mathrm{~h}$ prior to treatment with $20 \mu \mathrm{M}$ cisplatin for $1 \mathrm{~h}$. A clinical concentration $(10 \mu \mathrm{g} / \mathrm{ml})$ of lipid emulsion was selected as a solvent control to exclude the possible effect of lipids on the effects of propofol. Cisplatin significantly reduced the surviving fraction of cells at low (without GJs) and high density (with GJs) cultures in the two cells, and the survival rate was higher in the low-density cultures, compared with the high-density cultures. At a low density, pretreatment with propofol had no effect on cell viability in either cell type; however, propofol markedly increased the clonogenic survival of the cisplatin-treated cells in the high-density cultures. In the U87 cell, $4 \mathrm{~h}$ treatment with $15 \mu \mathrm{M}$ propofol increased the surviving fraction between $0.59 \pm 0.02$ and $0.75 \pm 0.03(\mathrm{P}<0.05)$, and in the HeLa cells, the viability of the cells increased between $0.48 \pm 0.02$ and $0.69 \pm 0.04(\mathrm{P}<0.05)$. These results indicated that propofol decreased cisplatin toxicity only when GJs were formed.

Cell viability measurement. The observation that propofol decreased the toxicity of cisplatin only in high density conditions, in which GJs were formed, suggested that the effect of propofol on cisplatin was mediated by GJs. In order to exclude the effects of cell viability on cisplatin toxicity and on GJ function, the present study first examined the effects of propofol on cell viability using an SRB assay. As shown in Fig. 2, propofol had no significant effect on cell viability, even at $100 \mu \mathrm{M}$ for $48 \mathrm{~h}$, in either the U87 cells or the Cx26-expressing HeLa cells. The viability of the cells under all experimental conditions was $>85 \%$, and no alterations in either cell morphology or adhesion were apparent (data not shown). As a result, the concentration of propofol used in the following experiments was between 1 and $100 \mu \mathrm{M}$.

Effect of propofol on GJ function. To test the hypothesis that propofol depresses the toxicity of cisplatin due to the presence of GJs, the effects of propofol on dye coupling between confluent U87 or Cx26-transfected HeLa cells were examined. GJ function was assessed using the parachute dye-coupling assay. As shown in Fig. 3A, treatment with 1, 5,15 and $30 \mu \mathrm{M}$ propofol for $4 \mathrm{~h}$ led to marked inhibition of the spread of dye between the donor cells and receiver cells, which occurred in a concentration-dependent manner, in the U87 cells. Treatment with $15 \mu \mathrm{M}$ propofol inhibited GJ function by $\sim 40 \%$, compared with the lipid-treated cells. Furthermore, as shown in Fig. 3B, $15 \mu \mathrm{M}$ propofol inhibited GJ function following treatment for 1, 4, 24 and $48 \mathrm{~h}$, and the inhibition rate was the highest at $48 \mathrm{~h}$ at almost $55 \%$.

In the Cx26-transfected HeLa cells, the induction of Cx26 expression with doxycycline was examined by western blot analysis (Fig. 4A and B), and the emergence of GJIC was examined using the parachute dye coupling assay (Fig. 4C).
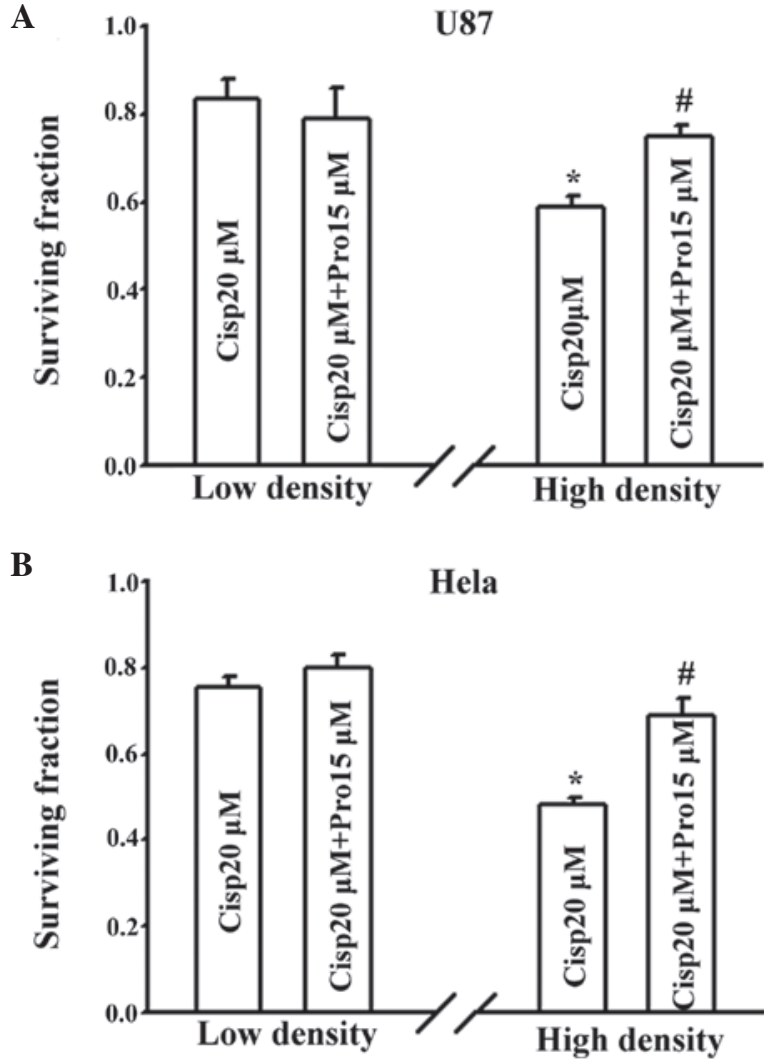

Figure 1. Effects of propofol on cisplatin toxicity in U87 and Cx26-expressing HeLa cells. Clonogenic survival of (A) U87 and (B) HeLa cells incubated with $20 \mu \mathrm{M}$ cisplatin for $1 \mathrm{~h}$, with or without, $15 \mu \mathrm{M}$ propofol pretreatment in low and high density cultures. Results are presented as the mean \pm standard error of the mean of three to five experiments. " $\mathrm{P}<0.05$, vs. low density group; ${ }^{\#} \mathrm{P}<0.05$, vs. cisplatin. Cisp, cisplatin; Pro, propofol; Cx, connexin.

Treatment with $1,5,15$ and $30 \mu \mathrm{M}$ propofol for $4 \mathrm{~h}$ significantly inhibited the function of the GJs composed of Cx26, which occurred in a concentration-dependent manner (Fig. 5A). Treatment with $15 \mu \mathrm{M}$ propofol inhibited GJ function by $\sim 35 \%$ at $4 \mathrm{~h}$ and $60 \%$ at $48 \mathrm{~h}$, compared with the lipid-treated cells (Fig. 5B). The above results indicated that propofol inhibited the function of GJs composed of $\mathrm{Cx} 43$ or $\mathrm{Cx} 26$ in a concentration- and time-dependent manner.

Effects of propofol on expression levels of Cx43 and Cx26. Changes in the number of GJs affected by the expression of $\mathrm{Cx}$ is one of the mechanisms by which propofol has been suggested to alter GJ function. In the present study, the expression levels of Cx43 and Cx26 were determined using western blot analysis. As shown in Fig. 6, treatment of the U87 cells with $15 \mu \mathrm{M}$ propofol for 1 and $4 \mathrm{~h}$ did not alter the expression levels of $\mathrm{Cx} 43$. However, by prolonging the treatment duration to 24 and $48 \mathrm{~h}$, propofol treatment led to decreases in the levels of $\mathrm{Cx} 43$, compared with the lipid emulsion group. Similarly, in the HeLa cells, $15 \mu \mathrm{M}$ propofol decreased the expression of $\mathrm{Cx} 26$ only when the cells were treated for $48 \mathrm{~h}$ (Fig. 7). Therefore, propofol reduced the function of GJs composed of $\mathrm{Cx} 43$ or $\mathrm{Cx} 26$ by decreasing the expression levels of $\mathrm{Cx}$ in long treatment durations. Consequently, these results confirmed the hypothesis that propofol depresses cisplatin toxicity by the inhibition of GJ function via altering the expression of Cxs. 

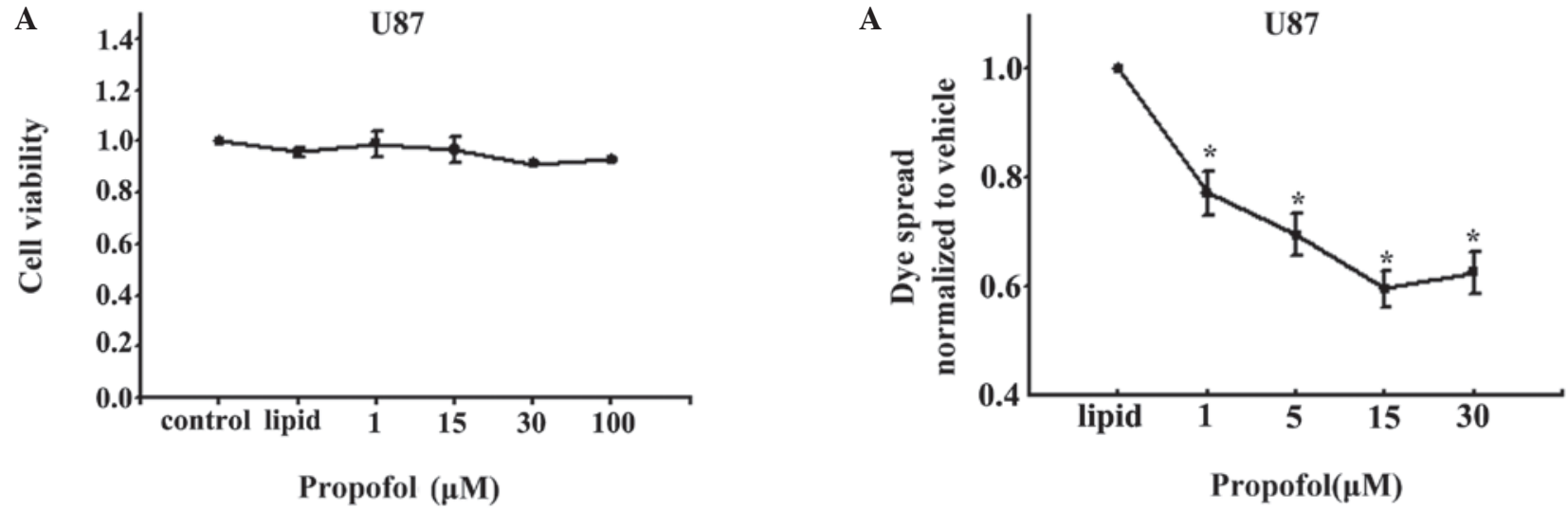

B
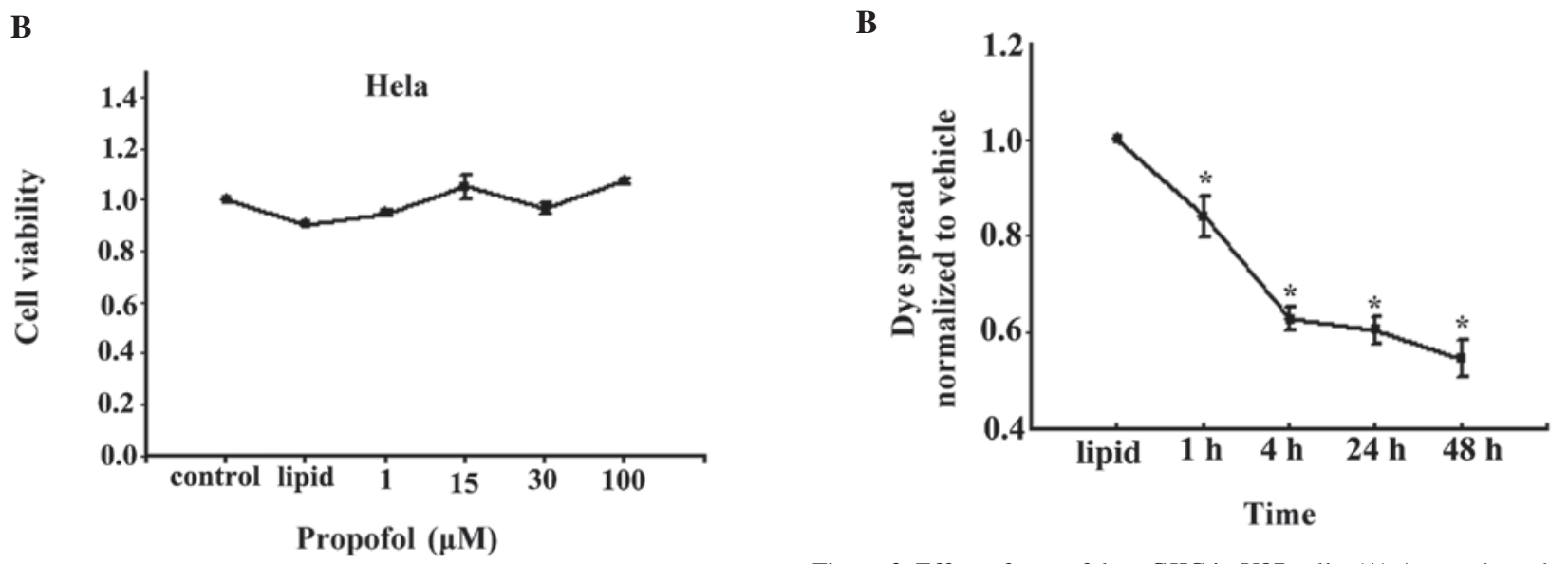

Figure 3. Effect of propofol on GJIC in U87 cells. (A) A parachute dye-coupling assay was used to assess the degree of GJIC following exposure to

Figure 2. Effects of propofol on cell viability. The viabilty of (A) U87 an (B) Cx26-expressing HeLa cells were determined. The cells were treated with the indicated concentrations of propofol for $48 \mathrm{~h}$ following being seeded into 96-well plates. Cell viability was then determined using a sulforhodamine B assay. Data are presented as the mean \pm standard error of the mean of three independent experiments. $\mathrm{Cx}$, connexin.

\section{Discussion}

$\mathbf{A}$

The present study demonstrated that propofol, at clinically relevant concentrations, significantly inhibited the function of the GJs formed by Cx43 or Cx26, and reduced the cytotoxicity of cisplatin by the inhibition of GJIC. The results showed that propofol inhibited the function of GJ channels, and decreased the expression levels of $\mathrm{Cx} 43$ or $\mathrm{Cx} 26$ in long-term treatment. This revealed a novel mechanism underlying the effects of analgesics in counteracting chemotherapeutic efficiency.

Cisplatin cytotoxicity was decreased when GJIC was inhibited and enhanced when GJIC was upregulated, as previously demonstrated $(8,24)$. In the present study, the cells were cultured in two conditions: Low density, in which GJs were not formed, and high density, which allowed the cells to contact each other to form GJs. As shown in Fig. 1, cisplatin toxicity was increased in the high-density culture with GJs, compared with the low-density culture without GJs, which was consistent with previous reports $(8,17,18,22)$. In addition, pretreatment with propofol at its EC50 significantly decreased cispaltin toxicity in the high-density culture in the U87 cells and Cx26-transfected HeLa cells, indicating that propofol depressed cisplatin toxicity only in the presence of GJs. $1,5,15$ and $30 \mu \mathrm{M}$ propofol. (B) GJIC was assessed using a parachute assay following exposure to $15 \mu \mathrm{M}$ propofol for 1, 4, 24 and $48 \mathrm{~h}$. Data are presented as the mean \pm standard error of the mean from three to six independent experiments. ${ }^{*} \mathrm{P}<0.05$, vs. lipid emulsion (lipid) group. GJIC, gap junction intercellular communication; $\mathrm{Cx}$, connexin.

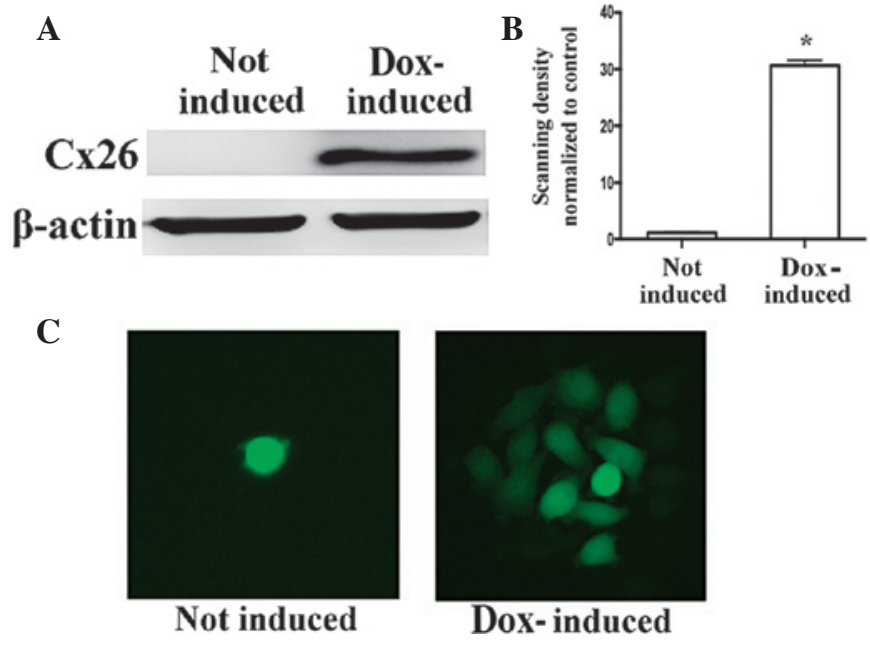

Figure 4. Doxycycline induces the expression of Cx26 and dye-coupling through junctional channels. (A) Western blot showing the expression of Cx26 following doxycycline $(1 \mu \mathrm{g} / \mathrm{ml})$ treatment. (B) Quantitative analysis of the western blot. (C) Fluorescence images show dye-coupling through gap junctions in the Cx26-transfected HeLa cells (original magnification, x200). $\mathrm{Cx}$, connexin. ${ }^{*} \mathrm{P}<0.05$ vs. the non-induced group.

Substantial evidence has suggested that GJIC is reduced or absent in numerous types of carcinoma (7,25-27), however, 
A

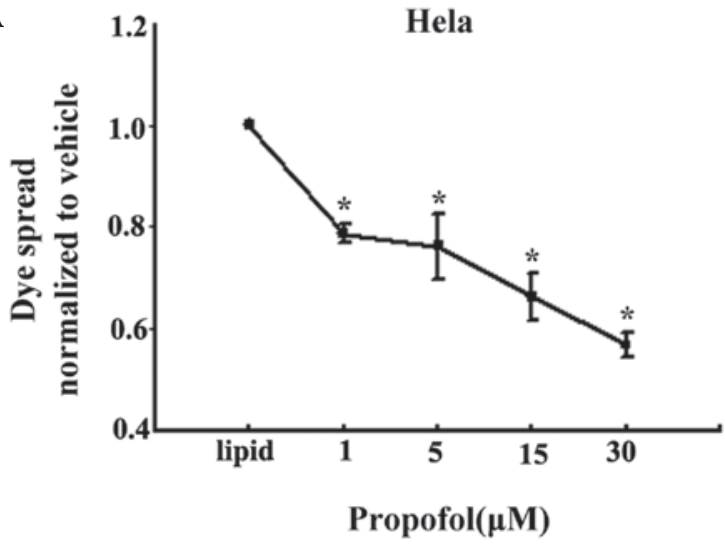

B

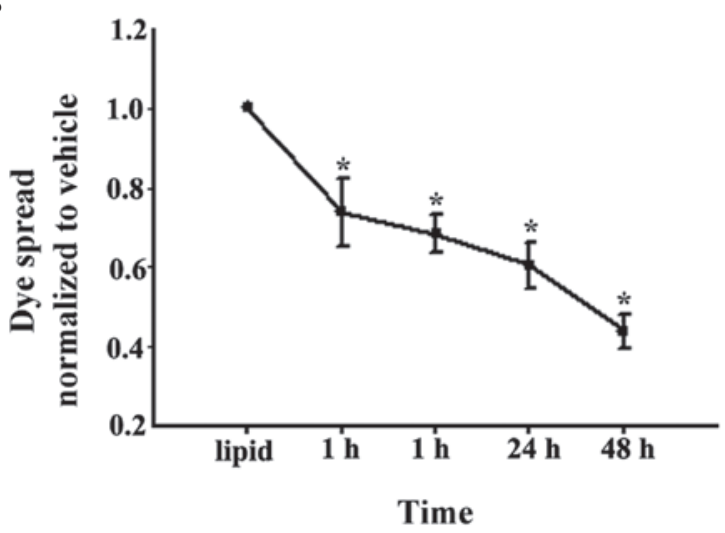

Figure 5. Effect of propofol on GJIC in Cx26-transfected HeLa cells. (A) A parachute dye-coupling assay was applied to assess the degree of GJIC following exposure to $1,5,15$ and $30 \mu \mathrm{M}$ propofol. (B) GJIC was measured using a parachute assay following exposure to $15 \mu \mathrm{M}$ propofol for 1, 4, 24 and $48 \mathrm{~h}$. Data are presented as the mean \pm standard error of the mean from three to five independent experiments. ${ }^{*} \mathrm{P}<0.05$, vs. lipid emulsion (lipid) group. GJIC, gap junction intercellular communication; Cx, connexin.

GJIC remains preserved in certain types of cancer $(28,29)$, and during the invasion and metastatic stages, an upregulation of GJIC has been observed in certain cancer cells with nominally defective GJs (30-32). In these GJs, which are derived from Cx26, Cx32 or Cx43, the effect of propofol on GJIC and how it is likely to impact the therapeutic efficacy of cisplatin requires consideration.

The present study demonstrated that treatment of the U87 or Cx26-transfected HeLa cells with propofol $(15 \mu \mathrm{M})$ for $1 \mathrm{~h}$ had no effect on the expression levels of Cx43 or Cx26. However, in contrast to our previous studies on Cx32 (17,18), the expression levels of $\mathrm{Cx} 43$ or $\mathrm{Cx} 26$ altered when the duration of propofol exposure was extended to 24 or $48 \mathrm{~h}$. These results indicated that long-term propofol exposure decreased GJIC, predominantly via downregulation of the protein levels of $\mathrm{Cx} 43$ or $\mathrm{Cx} 26$. However, the reduction of GJIC following short-term (1 and $4 \mathrm{~h}$ ) treatment with propofol may occur via a different manner. It is possible that short-term treatment with propofol caused aberrant localization of the Cx proteins without reducing their expression levels, as reported previously $(27,33)$, which requires further investigation.

In conclusion, the present study demonstrated that propofol affects the function of GJs formed of various types of Cxs, and demonstrated that propofol depressed the cytotoxicity of cisplatin in U87 glioma cells and Cx26-transfected HeLa
A
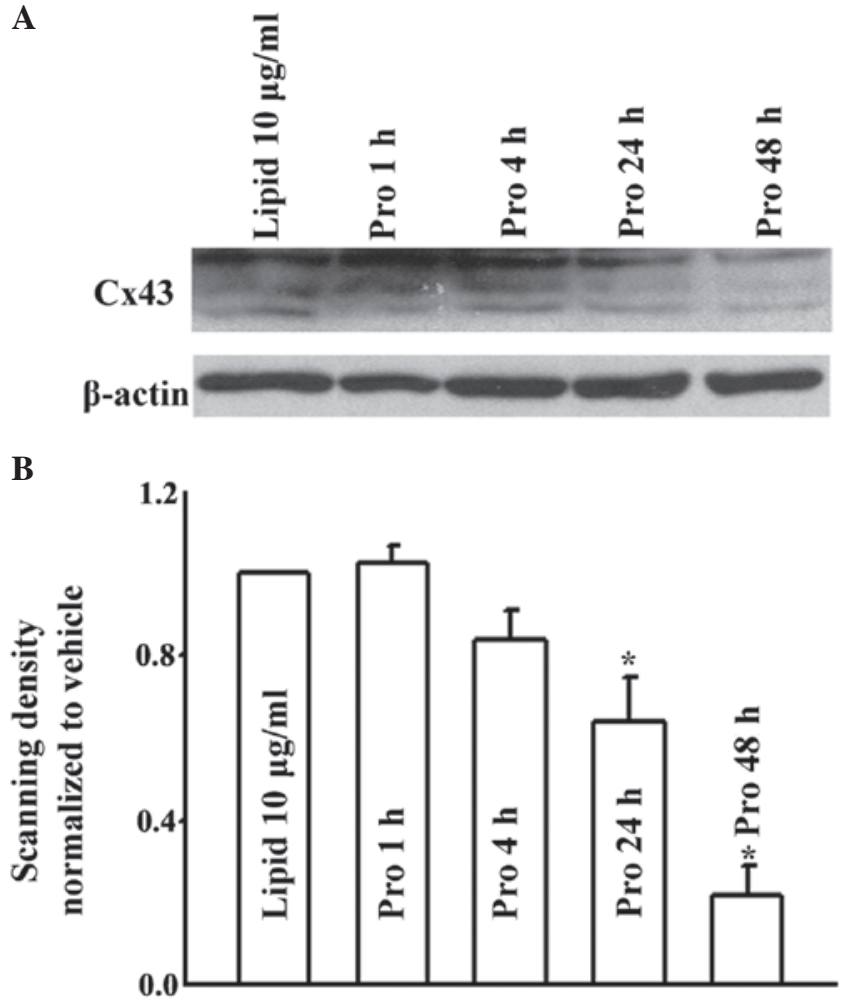

Figure 6. Effects of $15 \mu \mathrm{M}$ propofol on the expression of Cx43 in U87 cells (A) Western blotting was performed and (B) the results were quantified to assess the levels of $\mathrm{Cx} 43$ in U87 cells following exposure to $15 \mu \mathrm{M}$ propofol for $1,4,24$ and $48 \mathrm{~h}$. Data are presented as the mean \pm standard error of the mean of four to six independent experiments. ${ }^{*} \mathrm{P}<0.05$, vs. lipid emulsion (lipid) group. Pro, propofol; Cx, connexin.
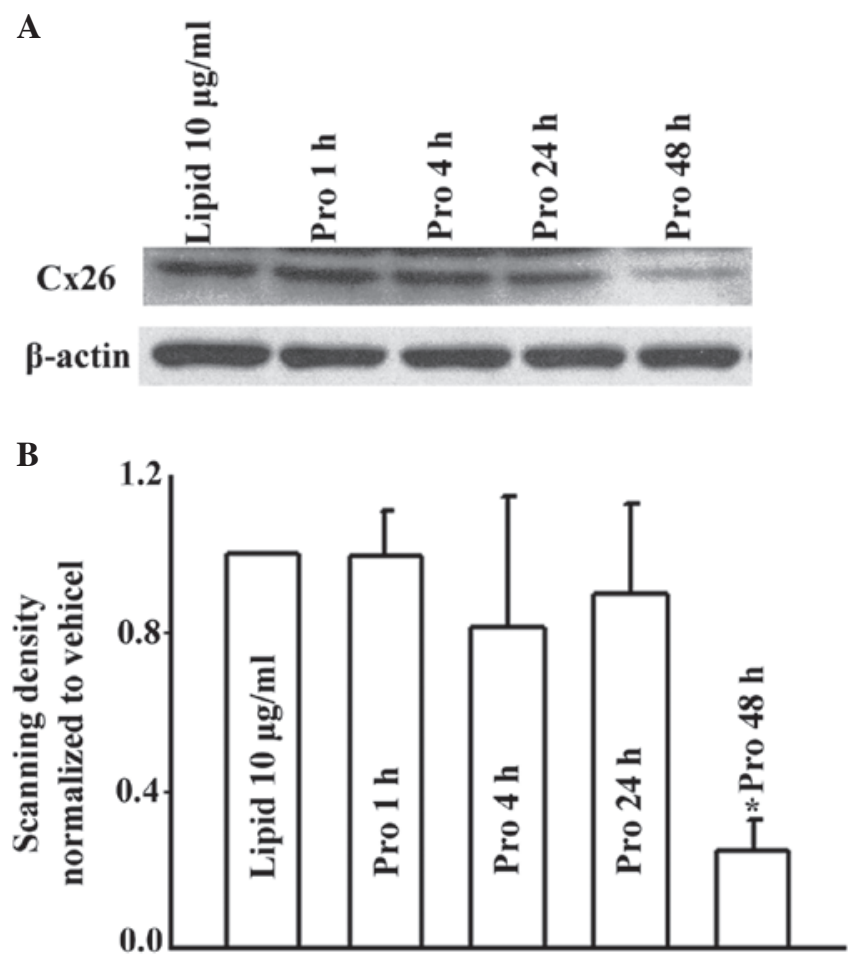

Figure 7. Effects of $15 \mu \mathrm{M}$ propofol on the expression of $\mathrm{Cx} 26$ in Cx26-transfected HeLa cells. (A) Western blotting was performed and (B) the results were quantified to assess the levels of Cx26 in HeLa cells following exposure to $15 \mu \mathrm{M}$ propofol for 1, 4, 24 and $48 \mathrm{~h}$. Data are presented as the mean \pm standard error of the mean of three to six independent experiments. ${ }^{*} \mathrm{P}<0.05$, vs. lipid emulsion (lipid) group. Pro, propofol; $\mathrm{Cx}$, connexin. 
cells through the inhibition of GJ activity. The results further indicated that long-term treatment with propofol decreased GJIC, predominantly via reductions in the expression levels of $\mathrm{Cx} 43$ and $\mathrm{Cx} 26$. Although the effects of propofol on chemotherapy and radiotherapy, and the underlying molecular mechanisms require further investigation, the results of the present study suggest that GJIC is one of the possible mechanisms.

\section{Acknowledgements}

The present study was supported by the National Natural Science Foundation of China (grant nos. 81373439 and 81473234), the Joint Fund of the National Nature Science Foundation of China (grant no. U1303221), the Grant for the Construction of Technique Plate for Evaluation of the Pharmacodynamics of New Drugs in Xinjiang from the Department of Science and Technology of Xinjiang province (grant no. 201233150), the Department of Science and Technology of Guangzhou, China (grant no. 201300000158) and the Grant for Development of Science and Technology from Department of Science and Technology of Guangzhou, China (grant no. 201300000158).

\section{References}

1. Sosinsky GE and Nicholson BJ: Structural organization of gap junction channels. Biochim Biophys Acta 1711: 99-125, 2005 .

2. Harris AL: Connexin channel permeability to cytoplasmic molecules. Prog Biophys Mol Biol 94: 120-143, 2007.

3. Maeda $\mathrm{S}$ and Tsukihara T: Structure of the gap junction channel and its implications for its biological functions. Cell Mol Life Sci 68: 1115-1129, 2011

4. Vinken M, Vanhaecke T, Papeleu P, Snykers S, Henkens T and Rogiers V: Connexins and their channels in cell growth and cell death. Cell Signal 18: 592-600, 2006.

5. Cronier L, Crespin S, Strale PO, Defamie N and Mesnil M: Gap junctions and cancer: New functions for an old story. Antioxid Redox Signal 11: 323-338, 2009.

6. Kandouz M and Batist G: Gap junctions and connexins as therapeutic targets in cancer. Expert Opin Ther Targets 14: 681-692, 2010.

7. Naus CC and Laird DW: Implications and challenges of connexin connections to cancer. Nat Rev Cancer 10: 435-441, 2010.

8. Wang Q, You T, Yuan D, Han X, Hong X, He B, Wang L, Tong X, Tao L and Harris AL: Cisplatin and oxaliplatin inhibit gap junctional communication by direct action and by reduction of connexin expression, thereby counteracting cytotoxic efficacy. J Pharmacol Exp Ther 333: 903-911, 2010.

9. Jensen R and Glazer PM: Cell-interdependent cisplatin killing by $\mathrm{Ku} / \mathrm{DNA}$-dependent protein kinase signaling transduced through gap junctions. Proc Natl Acad Sci USA 101: 6134-6139, 2004.

10. Azzam EI, de Toledo SM and Little JB: Direct evidence for the participation of gap junction-mediated intercellular communication in the transmission of damage signals from alpha-particle irradiated to nonirradiated cells. Proc Natl Acad Sci USA 98: 473-478, 2001.

11. Mesnil M, Piccoli C, Tiraby G, Willecke K and Yamasaki H: Bystander killing of cancer cells by herpes simplex virus thymidine kinase gene is mediated by connexins. Proc Natl Acad Sci USA 93: 1831-1835, 1996.

12. Weiser TG, Regenbogen SE, Thompson KD, Haynes AB, Lipsitz SR, Berry WR and Gawande AA: An estimation of the global volume of surgery: A modelling strategy based on available data. Lancet 372: 139-144, 2008.
13. Zhu M, Chen J, Yin H, Jiang H, Wen M and Miao C: Propofol protects human umbilical vein endothelial cells from cisplatin-induced injury. Vascul Pharmacol 61: 72-79, 2014.

14. Taheri Moghadam G, Hosseini-Zijoud SM, Heidary Shayesteh T, Ghasemi $\mathrm{H}$ and Ranjbar A: Attenuation of cisplathin-induced toxic oxidative stress by propofol. Anesth Pain Med 4: e14221, 2014.

15. Wentlandt K, Carlen PL, Kushnir M, Naus CC and El-Beheiry H: General anesthetics attenuate gap junction coupling in P19 cell line. J Neurosci Res 81: 746-752, 2005.

16. Huang F, Li S, Gan X, Wang R and Chen Z: Propofol inhibits gap junctions by attenuating sevoflurane-induced cytotoxicity against rat liver cells in vitro. Eur J Anaesthesiol 31: 219-224, 2014.

17. He B, Tong X, Wang L, Wang Q, Ye H, Liu B, Hong X, Tao L and Harris AL: Tramadol and flurbiprofen depress the cytotoxicity of cisplatin via their effects on gap junctions. Clin Cancer Res 15: 5803-5810, 2009.

18. Zhao Y, Liu B, Wang Q, Yuan D, Yang Y, Hong X, Wang X and Tao L: Propofol depresses the cytotoxicity of X-ray irradiation through inhibition of gap junctions. Anesth Analg 112: 1088-1095, 2011.

19. Koreen IV, Elsayed WA, Liu YJ and Harris AL: Tetracycline-regulated expression enables purification and functional analysis of recombinant connexin channels from mammalian cells. Biochem J 383: 111-119, 2004.

20. Papazisis KT, Geromichalos GD, Dimitriadis KA and Kortsaris AH: Optimization of the sulforhodamine B colorimetric assay. J Immunol Methods 208: 151-158, 1997.

21. Goldberg GS, Bechberger JF and Naus CC: A pre-loading method of evaluating gap junctional communication by fluorescent dye transfer. Biotechniques 18: 490-497, 1995.

22. Hong X, Wang Q, Yang Y, Zheng S, Tong X, Zhang S, Tao L and Harris AL: Gap junctions propagate opposite effects in normal and tumor testicular cells in response to cisplatin. Cancer Lett 317: 165-171, 2012.

23. White M and Kenny GN: Intravenous propofol anaesthesia using a computerised infusion system. Anaesthesia 45: 204-209, 1990.

24. Wang Y, Wang Q, Zhang S, Zhang Y and Tao L: Baicalein increases the cytotoxicity of cisplatin by enhancing gap junction intercellular communication. Mol Med Rep 10: 515-521, 2014.

25. Mesnil M, Crespin S, Avanzo JL and Zaidan-Dagli ML: Defective gap junctional intercellular communication in the carcinogenic process. Biochim Biophys Acta 1719: 125-145, 2005.

26. Loewenstein WR and Kanno Y: Intercellular communication and the control of tissue growth: Lack of communication between cancer cells. Nature 209: 1248-1249, 1966.

27. Leithe E, Sirnes S, Omori Y and Rivedal E: Downregulation of gap junctions in cancer cells. Crit Rev Oncog 12: 225-256, 2006.

28. Plante I, Stewart MK, Barr K, Allan AL and Laird DW: Cx43 suppresses mammary tumor metastasis to the lung in a Cx43 mutant mouse model of human disease. Oncogene 30: $1681-1692,2011$

29. Krutovskikh VA, Piccoli $\mathrm{C}$ and Yamasaki H: Gap junction intercellular communication propagates cell death in cancerous cells. Oncogene 21: 1989-1999, 2002.

30. Czyz J: The stage-specific function of gap junctions during tumourigenesis. Cell Mol Biol Lett 13: 92-102, 2008.

31. Kanczuga-Koda L, Sulkowska M, Koda M, Rutkowski R and Sulkowski S: Increased expression of gap junction protein-connexin 32 in lymph node metastases of human ductal breast cancer. Folia Histochem Cytobiol 45 (Suppl 1): S175-S180, 2007

32. Saito-Katsuragi M, Asada H, Niizeki H, Katoh F, Masuzawa M, Tsutsumi M, Kuniyasu H, Ito A, Nojima H and Miyagawa S: Role for connexin 26 in metastasis of human malignant melanoma: Communication between melanoma and endothelial cells via connexin 26. Cancer 110: 1162-1172, 2007.

33. Tang N, Wang Q, Wu DP, Zhang SZ, Zhang Y and Tao L: Differential effects of paclitaxel and docetaxel on gap junctions affects their cytotoxicities in transfected HeLa cells. Mol Med Rep 8: 638-644, 2013. 